
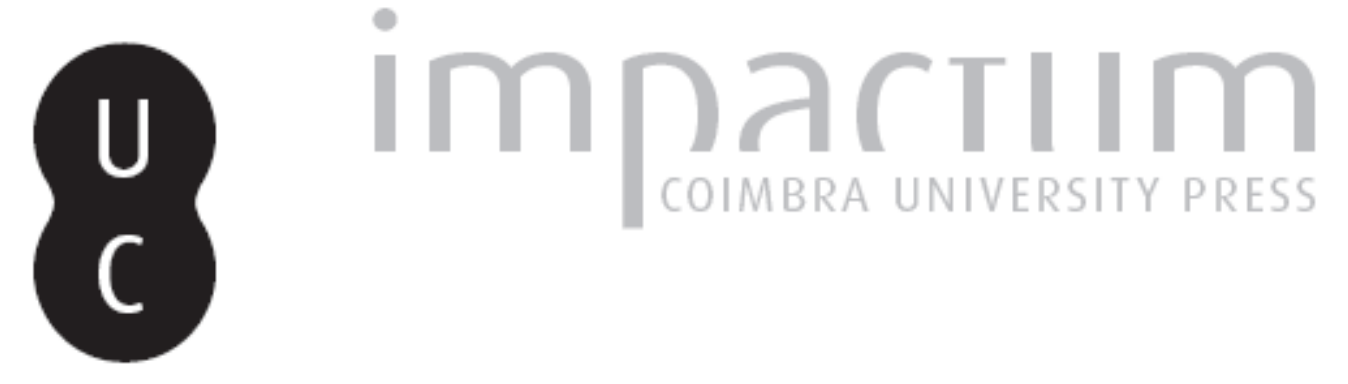

\title{
A dimensão ética em arquitectura
}

Autor(es): $\quad$ Murtinho, Vitor; Tavares, Domingos

Publicado por: Editorial do Departamento de Arquitectura

URL persistente:

URl:http://hdl.handle.net/10316.2/37411

DOI:

DOI:http://dx.doi.org/10.14195/0874-6168_1_6

Accessed : $\quad$ 26-Apr-2023 10:38:42

A navegação consulta e descarregamento dos títulos inseridos nas Bibliotecas Digitais UC Digitalis, UC Pombalina e UC Impactum, pressupõem a aceitação plena e sem reservas dos Termos e Condições de Uso destas Bibliotecas Digitais, disponíveis em https://digitalis.uc.pt/pt-pt/termos.

Conforme exposto nos referidos Termos e Condições de Uso, o descarregamento de títulos de acesso restrito requer uma licença válida de autorização devendo o utilizador aceder ao(s) documento(s) a partir de um endereço de IP da instituição detentora da supramencionada licença.

Ao utilizador é apenas permitido o descarregamento para uso pessoal, pelo que o emprego do(s) título(s) descarregado(s) para outro fim, designadamente comercial, carece de autorização do respetivo autor ou editor da obra.

Na medida em que todas as obras da UC Digitalis se encontram protegidas pelo Código do Direito de Autor e Direitos Conexos e demais legislação aplicável, toda a cópia, parcial ou total, deste documento, nos casos em que é legalmente admitida, deverá conter ou fazer-se acompanhar por este aviso.

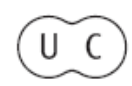




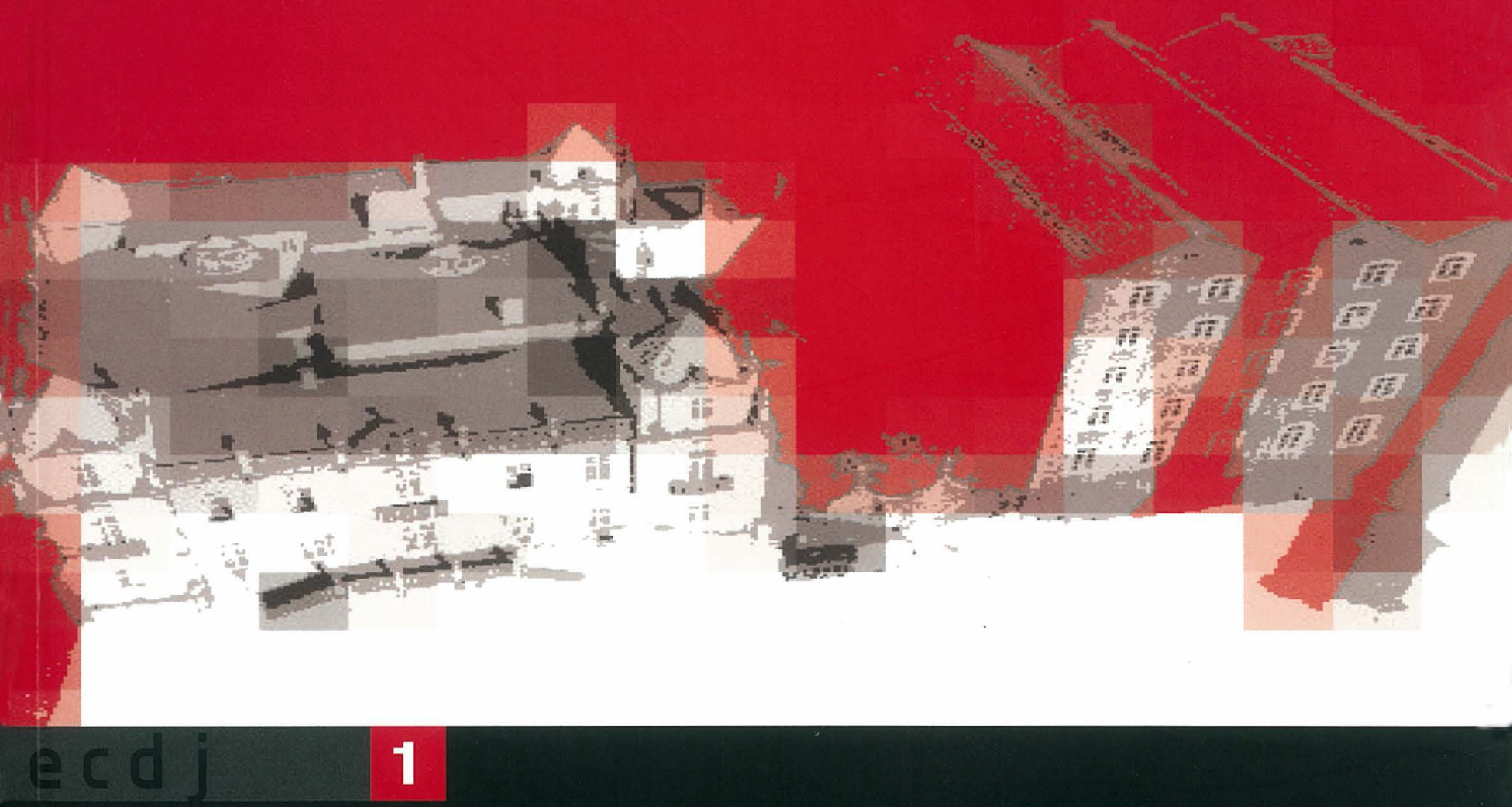

fctuc / departamento de arquitectura

\section{a polémica do Freixo Fernando Távora} alexandre alves costa | antónio olaio joão paulo rapagão | jorge figueira josé antónio bandeirinha

(2) 


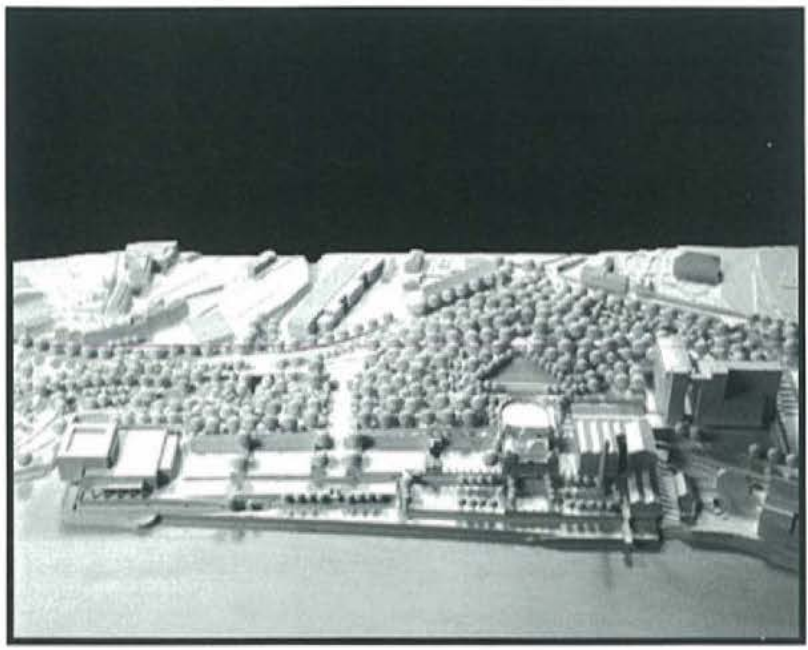


[a dimensão ética em arquitectura]

Vitor MURTINHO + pomincos Tavares

“Não suba o sapateiro além do chinelo." | PLiNIO

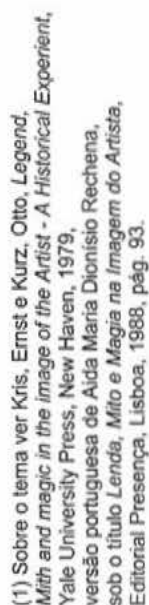

Segundo o relato, um sapateiro chamou à atenção de Apeles para um erro de representação no sapato de uma das figuras por ele pintadas, razão pela qual o artista Ihe ficou agradecido; mas quando este - agora com confiança - prosseguiu pondo em causa a representação do pé, estava criado o episódio que viria a proporcionar o célebre ditado(1).

> Como ilustração serve o facto, como pretexto, para caricaturar o estado das coisas no mundo do exercício da actividade de arquitecto: relação entre crítica e profissional, imposição da estética pelo cliente (público ou privado), solidariedade entre arquitectos e comportamento público dos elementos representativos da classe.

> Daí, talvez possamos afirmar, que trabalhando quase sempre sem rede somos profissionalmente seres demasiado expostos no espectáculo do mundo. 


\section{$1 \mid$}

Infelizmente, na profissão de arquitecto e no que concerne ao dever do respeito pelo outro igual, ainda há muito por fazer. Segundo Kant, "o dever de amar o próximo pode também exprimir-se assim: É o dever de transformar em meus os fins dos outros (apenas com a restrição de não serem imorais). O dever de respeitar o meu próximo está contido na máxima de não degradar a nenhum outro homem, transformando-o apenas em meio para os meus fins (não exigir que o outro se tenha de rebaixar a si próprio para se entregar ao meu fim)"(2). De facto, cada vez com maior normalidade, demasiadas vezes com excessivo acutilamento e agressividade, se assiste na praça pública a acesos debates e manifestações de desagrado para com determinadas intervenções arquitectónicas de colegas e que em nada abonam a prática da profissão ou dignificam a Arte. Assim a imposição de uma opinião diferente faz-se por recurso aos media - forma warholiana de fama -, funcionando estes como meio de propagação de uma opinião ou convicção e que por si só não valida o veiculado. É estranho que algumas dessas magistrais opiniões venham de colegas onde da obra pouco se sabe, de palavra escrita não se conhece o rasto e dos seus gestos públicos somente nos recordamos de 5 minutos de fama. Sabemos que em termos jornalisticos só é notícia o gesto infame do homem morder o cão, pena é que demasiadas vezes a arquitectura seja notícia porque os seus profissionais se mordem uns aos outros na praça pública.

> Numa profissão plena de responsabilidade como é o caso da de arquitecto - até pela visibilidade do acto - lamentamos que normalmente a crítica do projecto se faça maioritariamente pelos defeitos. Que raramente se critique uma obra através da ênfase dos aspectos positivos mas quase sempre pela negativa; como se de repente todos fôssemos excelentes profissionais, com projectos magistralmente concebidos e com primor executados; não precisamos nós - ainda - de usar a desculpa do empreiteiro para justificar e imprecisão das nossas dúvidas e como razão base das nossas incertezas e incoerências de concretização em obra.

> Daí, estamos em condições de afirmar, que o princípio da crítica em arquitectura é feito quase sempre do mesmo modo, como não conseguimos demonstrar o facto de sermos melhores que os outros, 
logo tratamos de esclarecer que os outros é que são pior que nós; e essa é a verdadeira razão da desvalorização do trabalho profissional dos outros colegas. É óbvio que, como situação de dependência, a arquitectura precisa do crítico, da mesma forma que também só nos encontramos a nós mesmos no nosso rosto com o espelho dos outros(3); a boa crítica é a consciência da boa arquitectura. Mas criticar raramente se assemelha a critica.

> É do senso comum que um bom profissional não é somente um bom técnico - como a boa arquitectura não se confina somente à boa construção - mas alguém que actua segundo um conjunto de valores relacionados à boa prática da sua profissão; conjugação do saber técnico e do saber moral. Neste caso o saber técnico supõe o domínio do engenho de aplicar os meios adequados a um determinado fim, independentemente de este ser bom ou mau, enquanto o saber moral supõe a atitude prudente de avaliação e deliberação dos meios técnicos de forma a garantir um fim bom; não é nosso propósito discorrer sobre a questão da vontade de bem fazer e do resultado contrário, naquilo que se poderia designar como a responsabilidade da ignorância individual ou colectiva: boa vontade, sem laxismo, mas com mau resultado.

> Se na matemática é suposto que, independentemente do caminho seguido, a solução seja sempre igual, em arquitectura isso é determinantemente falso. Se por objectivo final, deve estar subjacente o bem comum como resposta a um programa ou necessidade, existem sempre, mesmo assim, várias soluçöes; neste âmbito, não existindo dúvida que é objectivo da arquitectura dar resposta ao senso comum, impõe-se salientar que quer os critérios para a compreensão do fazer bem, quer o sentido não consensual do bem colectivo, propiciam um vasto cambiante de soluções de projecto. E, neste caso, a adopção de uma delas, mesmo que se apresente como a mais provável, tem presente que se podem simultaneamente oferecer outras que em julgamento se apresentem também como prováveis ecdj $8+49$ existindo mesmo situações onde a história vem desvalorizar algumas avaliações que no seu tempo foram esgrimidas por bocas - ditas avalizadas. Recordamos o célebre caso, em Paris, do Protesto dos Artistas, publicado no Le Temps em 14 de Fevereiro de 1887, contra a erecção da Torre Eiffel e onde como signatários constam personagens 
tão ilustres como Guy de Maupassant ou Alexandre Dumas Filho,

entre outros. Nesta polémica, um conjunto diversificado de individualidades - escritores, escultores, arquitectos, pintores apresentam o argumento que a "construção da inútil e monstruosa" Torre Eiffel iria destruir a "beleza intacta" da cidade(4). Neste caso, assiste-se à revalorização do objecto de intervenção - a cidade -, pelo facto duma não aplicação mecânica e consensual do princípio de actuação, mas que por adequada avaliação em função da diversidade da situação, permite obter um resultado plenamente satisfatório; como em outras situações, teria sido mais fácil manter o status quo em vez de correr o risco da mudança e o concretizar duma nova situação. Aqui, a avaliação de tendências entre contra e pró, ou seja, entre a geração que viu nascer a torre e as seguintes que aprenderam a conviver com ela, de certeza que tem importância para os últimos, na medida em que esta construção se tornou, inexoravelmente, em elemento marcante na cidade no sentido lynchiano do termo. $\mathrm{Na}$ actualidade esta construção - erigida para assinalar a glória da arquitectura do ferro durante a Exposição Universal de 1889 - faz parte do imaginário popular, tendo pelo efeito adquirido o estatuto de verdadeiro ex-libris da cidade e como tal será de todo inquestionável a sua conservação.

> Quando na contemporaneidade pensamos no caso do Palácio do Freixo e nas moagens Harmonia, será inequívoco que o valor que o palácio teve - como elemento isolado e organizador do sítio - aquando da sua construção será, de forma inequívoca, superior à mais-valia que a fábrica possa porventura acrescentar ao conjunto; isto independentemente da importância própria das moagens como peça de valor industrial com uma estrutura pré-fabricada. Neste sentido, julgamos que o estabelecimento duma opinião alicerçada numa visão romântica, onde a habituação visual faz norma sobre aquilo que constitui o valor patrimonial, é decididamente um factor perigoso para avaliação e qualificação do espaço urbano. O palácio foi concebido e organizado em torno de uma estrutura verde também ela ao mesmo tempo organizada e na qual foi posteriormente construído a Harmonia, não com o objectivo de reorganizar a área envolvente mas tão somente porque essa foi uma hipótese dada a disponibilidade do terreno e a sua boa acessibilidade fluvial e viária. E se, tal como o 
profissional interveniente verificou, as duas construções são incompativeis em termos da sua manutenção no actual sítio, na medida em que a fábrica subverte totalmente a função e o espírito do palácio - como que o espezinha e aniquila -, então preferimos o último, sabendo que a primeira, como estrutura desmontável que é - na sua génese - pode ser montada noutro sítio: esta atitude é um acto de coragem e de higiene. Pelo que o refutar da intervenção em causa, só será admissível se na operação sugerida os custos se determinem como incomportáveis, obrigando o arquitecto, como dever, a propor algo que se vislumbre materialmente possível. Como o proposto parece ser realizável e exequível, sem recurso a meios tecnológicos extraordinários e economicamente sustentável, não existe razão consistente para a sua não implementação. Agindo o arquitecto em consciência - nesse tribunal interno do homem - só resta esperar que se realize a conviç̧ão do desejo e a consciência moral, mesmo que outros - por promoção - se ocultem sob a aparente máscara severa do dever. Feita que foi a avaliação das hipóteses e a racionalidade dos fins, importa dinamizar a solução para que com resultados valorativos, se cumpra a história fazendo-se a obra. Segundo Espinosa, "quem decidiu fazer alguma coisa e a levou a cabo, dirá que a sua obra está perfeita; e não só esse, mas também todo o que tiver conhecido exactamente a intenção do autor de tal obra e o seu fim" mas, quando as pessoas, não estão plenamente dentro do assunto, ou quando "os homens começaram a formar ideias universais e a escogitar modelos"(5), logo emergem opiniões indiciadores doutras hipóteses, mas que de facto - dizemos nós - resultam na sua maior parte de posições deficientemente formadas e pouco reflectidas tendo por resultado somente, na maior parte das vezes, não a contribuição para o solucionar do problema, mas o puro acto de protagonismo. E Távora sabe disso pois havia escrito que "o arquitecto, pela sua profissão, é por excelência um criador de formas, um organizador do espaço; mas as formas que cria, os espaços que organiza, mantendo relações com a circunstância, criam circunstância e havendo na acção do arquitecto possibilidade de escolher, possibilidade de selecção, há fatalmente drama"(6).

> Para completar e se perceber a importância do trabalho do mestre, como afirmou Luiz Trigueiros: a minha reconciliação com a obra de 
Távora ocorreu quando percebi que ao uso da sensibilidade se acrescentavam agora, e em simultâneo, o uso das capacidades da razão e da cultura, permitindo assim um total domínio das intervenções com base na totalidade que procurava(7).

\section{2।}

Nunca como hoje sentimos a necessidade duma ética que respeite a diversidade cultural das sociedades, das corporações, de cada individuo e que, simultaneamente, assuma foros universalistas. $\mathrm{Na}$ sociedade moderna a generalidade dos comportamentos, o pluralismo das solicitações e o regime concorrencial, pressupõem o estabelecimento de vincadas orientações axiológicas e a adopção de normativas abstractas para os procedimentos morais. Como modo de garantia e de regulamentação do pluralismo disciplinar - não confundir com o comportamental - interessa sobretudo a adopção de modelos abstractos reguladores da prática deontológica. Neste contexto a postura ética, onde prevalecem valores como a justiça, a liberdade, o bem e a moral, deve ser quotidianamente adoptada como factor orientador da vida em classe ou em sociedade. Se reflectirmos a um nível de credo, por exemplo na tradição cristă prevalece o princípio da concepção religiosa da consciência como manifestação da voz suprema que, como centro unificador do indivíduo ou manifestação interiorizada, define toda a sua orientação comportamental. Não é por acaso que São Paulo no Novo Testamento defende a necessidade de seguir os ditames da própria consciência e o dever de respeitar a consciência alheia(8). Inerente ao próprio conceito de liberdade individual não está sempre subjacente a orientação que esta termine no momento em que colide com a liberdade do outro?

> Todos os princípios normativos e comportamentais devem ser orientados por mandamentos de simetria e de reciprocidade entre os diferentes sujeitos de um determinado grupo onde os arquitectos não constituem excepção. A constatação da necessidade de uma ética com cariz deontológico, tem por objectivo definir o devido e o correcto para uma classe e, portanto, estabelecer o quadro normativo do justo(9). Subjacente a este enunciado está a incarnação de valores e sentimentos, referentes à adopção duma consciência moral que, com 
prudência, veicula o acto: orientado por consciencialização do socialmente permitido e actuação através do moralmente correcto. Neste caso, a moralidade de uma determinada acção resulta, quase sempre da intenção, ou seja, do motivo ou móbil pelo qual se agiu: questão de consciência.

> É pela admissibilidade da pluralidade, ou variante do modo de concretização do arquitectónico, para o qual converge uma diversidade cultural e testemunhos antropológicos, que se deve admitir um sentimento generalizado de tolerância nunca compatível com o laxismo. Face à inexistência duma única verdade e axiologia em Arquitectura, que nos faz duvidar de critérios singulares para a intervenção, importa encontrar valores plurais que legitimem a prática profissional. Seriam eles: ética, dever, rigor, competência, responsabilidade.

- Segundo Botta, a arquitectura é uma disciplina ética antes mesmo de ser estética. Na génese ao acto de fazer arquitectura está inerente a preocupação moral de promover e garantir valores humanos que depois encontram sequência na fruição posterior do espaço. Por isso mesmo, após materialização edificada, esses valores tornam-se direitos legítimos dos utentes e da comunidade. Daí que o autor designe como acto ético o acto de projecto, na medida em que a legitimação do trabalho realizado, quando passa do virtual para o real, deve contar com a garantia da fruição do utente e que nessa qualidade representa a comunidade(10).

> Por outro lado, o sentido ético da profissão terá que determinantemente passar pelo princípio: "Age a respeito de todo o ser racional (de ti mesmo e de outrem) de tal modo que ele na tua máxima valha simultaneamente como fim em si, é assim no fundo idêntico ao princípio: Age segundo uma máxima que contenha simultaneamente em si a sua própria validade universal para todo o ser racional. Pois o facto de eu, no uso dos meios para qualquer fim, dever restringir a minha máxima à condição da sua validade universal como lei para todo o sujeito, equivale exactamente a dizer: o sujeito dos fins, isto é o ser racional mesmo, não deve nunca ser posto por fundamento de todas as máximas das acções como simples meio, mas como condição suprema restritiva no uso dos meios, isto é sempre simultaneamente como fim"(11). Neste âmbito, o princípio que 
norteia a acção, deve supor que o acto, por vontade expressa do sujeito, coincida e por isso constitua a lei universal.

> Este sentido ético deve ser aduzido de fundamentos como o carácter deontológico e o moral. Todos os conceitos morais devem ter origem apriorística e resultar de uma educação salutar, funcionando como princípios supremos de prática quotidiana. Será assim uma formação que se iniciará no berço e que terá grande desenvolvimento até à juventude, através da dita instrução moral e da formação da razão prática e do juízo. Para isso, seria óptimo que a razão determinasse a vontade enquanto faculdade de escolher só aquilo que a primeira reconhece como necessário ou seja bom(12). "Que vontade correspondesse a uma força interior e não a uma manifestação por obrigação ou por mandamento. Todo o procedimento deve ser racional e exercido com total dignidade, não podendo através do exercicio profissional vir a envergonhar-se o grupo. O propósito do exercício deve pressupor a lealdade nas intenções e uma perseverança na obediência a princípios bons: "Porque cria circunstância - positiva e negativa - a sua acção pode ser benéfica ou maléfica e daí que as suas decisões não possam ser tomadas com leviandade ou em face de uma visão parcial dos problemas ou por atitude egoísta de pura e simples satisfação pessoal. Antes de arquitecto, o arquitecto é homem, e homem que utiliza a sua profissão como um instrumento em benefício dos outros, da sociedade a que pertence"(13).

3 I

Outra questão - também importante - tem a ver com os códigos de conduta e as opiniões que os representantes da classe devem ter, quer nos actos públicos, quer no exercício normal da sua actividade. Ainda e no que cumpre à profissão tem de existir a consciência clara de que quem tem por difícil missão - a estatuto de acumular com a prática corrente - a representação de outros, deve ponderar ainda com maior cautela as suas posições em público. Este facto prende-se com o risco de para a generalidade dos ouvintes poder causar alguma confusão e conduzir ao equívoco de dar uma legibilidade a uma mensagem que querendo ser pessoal pode ser interpretada como vontade do colectivo. 
Sabemos que na vida pública, cada indivíduo, através do seu comportamento representa todo o grupo. Como disse António Olaio: "Para nós fazer sentido, tem de existir a ideia nós. E nós só existirá como ideia se for, simultaneamente, a globalidade e cada um"(14); assim, o colectivo revê-se no individual e o individual faz a imagem do colectivo. Daí que importe pois reforçar que a responsabilidade acrescida de quem por ser eleito é mais imagem, tem por dever ter grande contenção nos actos e nas palavras porque se contestar um seu igual, existe o risco de como legibilidade desse acto ser entendido como repreensão da classe; e ao existir tal comportamento, perde a legitimidade para representar os colegas ou, pior ainda, para os defender no exterior quando disso for o caso. Ao representado é pedido ética, competência e rigor, do representante espera-se solidariedade e responsabilidade; o representado reconhece a autoridade que por sua vez o representante deve exercer com determinação, descrição e - sobretudo - muita humildade.

\section{4।}

Quando em caso de divergência de opinião - o que pode ser salutar dentro da corporaçăo - esta é esgrimida na "praça pública", com o debitar de argumentação técnica perante uma audiência pouco familiarizada com os métodos e conteúdos intrínsecos à prática arquitectónica, só favorece quem por educação supõe que essa profissão abrange matérias facilmente assimiláveis pelo seu senso que julga comum. Em arquitectura, pelo facto de se tratar duma disciplina muito próxima do quotidiano das pessoas e muito marcante ao nível da formação da sua personalidade, cria-se a expectativa que a primeira pode - porque diz muito respeito aos segundos - contar com a sua opinião "avalizada". Daí que, seja uma situação normalmente aceite a integração de elementos representativos de órgãos de poder técnicos ou não - em equipas de selecção de projectos, ou quando não é só a estes que cumprem as decisões, com ou sem consulta especializada de profissionais. Sabendo que a última decisão é sobretudo política, tal como a primeira de dinamização do processo que leva ao projecto, podemos afirmar que uma grande quota parte da arquitectura que temos - o fautor dessa situação -, deve-se mais à 
decisão de outros do que aos arquitectos. Por vezes, sofremos demasiado, como dizia Gaston Berger ao ver a sabedoria separada do poder, para que não aspiremos à colaboração dos que definem o desejável e dos que sabem o que é possivel(15). Assim o que seria desejável, era a cumplicidade entre o poder e o saber, era a humildade dos que podem acatando e implementando as decisões dos que sabem.

> O homem, como ser social, amiúde adopta a perspectiva e a força do grupo, julgando nessa espécie de super ego, encontrar a legitimidade conceptual de opções que respeitam ao bom, ao bem, ao belo...

$\mathrm{E}$ a aderência a estas ideias, permite-lhe mais facilmente a integração em uma determinada classe ou capela social(16). Esta situação constitui um valor seguro para a manutenção e ascensão no grupo; daí a compreensibilidade da adopção de matrizes estáveis de comportamento e de gosto. Deste modo, o olhar do colectivo determina frequentemente o olhar individual onde a conveniência social funciona como filtro homogeneizador(17).

> Também culturalmente, existe uma predisposição inata para o silêncio quando sob o consenso generalizado duma vontade se camufla uma decisão, cuja maioria que a determinou, evitou reflectir. Por outro lado, quando uma minoria ousou pensar uma solução, mas porque vai sobrepor-se à inércia do status quo, colide com a mentalidade dominante, logo surgem por oportunidade as vozes discordantes.

> Sabemos que a transformação do ambiente edificado se rege por um ritmo bem mais lento do que o da vida das pessoas. E como o património edificado é parte integrante da nossa memória, ancorandose na mente - através da recordação e como factor de estabilização emocional e psíquica - faz com que a reprodução de um determinado modelo ou tipo seja mais facilmente assimilado ou adoptado por uma sociedade.

> Sendo o arquitecto, sobretudo, um operador da mentalidade, pode-se compreender facilmente a inércia associada aos cidadãos no que concerne à mudança dessa mesma mentalidade. Agora se misturarmos a esta perspectiva de inércia dos outros, a frescura do argumento que quotidianamente nós arquitectos debitamos em vãos duelos, feitos de golpes baixos e sem códigos de procedimentos e honra, obtemos o espelho da arquitectura deste país a que Eça de 
Queiroz chamou sitio. Se pode parecer legítimo que quem tem poder, o queira usar em todas as circunstâncias e em plenitude de acto, não podemos continuar a admitir que sejamos nós - os arquitectos - a conceder os argumentos, para deixarmos de decidir o alcance dos nossos actos e que, com essa atitude, diminuamos a nossa avalizada autoridade, transferindo-a para quem - não deveria mas efectivamente decide. Talvez por isso, como oralmente repete múltiplas vezes Alves Martins citando Rogério de Azevedo: "a arquitectura é uma bola, onde toda a gente se rebola e o arquitecto é que se amola."

> Em termos premonitórios escreveu Távora: "É impossível para os homens de hoje, poderem ver o resultado dos seus esforços; porém as grandes obras e as grandes realidades pertencem não a indivíduos, mas a uma comunidade constituida não só pelos presentes como pelos que hão-de vir, e dentro deste espírito ficaremos contentes em saber que as gerações vindouras obterão as soluções que sonhamos e para as quais colaboramos, sem no entanto ter o prémio da sua completa realização"(18). Quando pensamos no Freixo, o dito anterior constitui a certeza e a esperança de quem, a pretexto do deontológico, viu uma sólida razão para a escrita. 